\title{
Meaning and Future of Emotion-based Marketing Communication in New Marketing Era
}

\author{
Min-Wook Choi
}

\begin{abstract}
The objective of this study is to scrutinize the meaning and future of emotion based marketing communication in new marketing era. First, this study examined the concept and relation of marketing, brand and emotion. Then, extracted emotion related marketing concept in new marketing era. And it proposed application direction of emotion to marketing communication in the future. In new marketing era, the application of emotion to marketing communication will increase. What is important is the direction of application of emotion to marketing communication. The important directions of application are as below. First direction is collaboration. For effective application of emotion to marketing communication, the collaboration with other field is necessary. Second direction for effective application of emotion to marketing communication is creativity. Like advertising, the creativity is important in the use of emotion in marketing communication. The third application direction of emotion to marketing communication is long term perspective. The goal of emotional marketing or emotional communication is not short term sales increase. They should be viewed as a variety of efforts to engage with consumers rather than immediate results or effects. The forth application direction of emotion to marketing communication is relevance with brand. Even though emotional marketing or emotional communication is fun, touching, and creative, if it has no relation with brand, desired goal cannot be accomplished. In the situation where it is difficult to differentiate brand from others by quality of products, marketing communication using emotion will become a major means of brand differentiation.
\end{abstract}

Keywords : Contents marketing, Emotion, New marketing communication, Storytelling marketing

\section{INTRODUCTION}

$\mathrm{R}$ ecently, the use of emotion is increasing in various fields of marketing communication. What is unusual is that the importance and use of emotion is increasing in the new marketing environment based on digital technology. This can be predicted as technology develops and people depend on the machine, people find and put emphasis on the emotions of the human nature. The main point of brand differentiation in the past was difference of the physical property of the product. But the main point of brand differentiation today is the emotional solidarity that consumers perceive about the brand. This emotional solidarity is the basis for establishing and maintaining a long-term relationship with the brand.

Revised Manuscript Received on July 22, 2019

* Correspondence Author

Min-Wook Choi*, Department of Advertising \& Public Relations, Namseoul University, Cheonan, South Korea. Email: mwchoi@nsu.ac.kr

Though it has become an old word, it is increasingly difficult to differentiate itself from competitors in terms of the physical characteristics of products in today's marketing situations. In addition, the objective image alone is not enough to capture consumers' hearts in fierce competition. It is time to emphasize appealing to the human emotion beyond reason. Especially, the significance of emotion increases in new media marketing communication where the importance of social media increases. Social media is a suitable platform for expressing the identity of an individual or expressing the value of an individual through the ownership and sharing of the brand. When marketing communication is conducted, companies can stimulate emotional parts of human beings through social media, thereby inducing active participation of consumers.

In this context, this study intends to examine the use of emotion in the recent new marketing communication era. Specifically, this study will first examine the concept of emotion, and the meaning of emotion in marketing and brand. Then, this study will look at concepts in which emotion is important in new marketing communication, and think about direction of application of emotion in new marketing communication in the future.

\section{MARKETING, BRAMD AND EMOTION}

Emotion is a personal and subjective feeling that is instantly and automatically experienced when perceiving an object, or when in a particular environment. Emotion is ambiguous feeling which is inherently complex and comprehensive, and has personal and dynamic characteristics. In addition to personal circumstances, social and cultural factors play an important role in influencing individual emotion.

Today, the importance of emotions throughout marketing is increasing day by day. By looking at the difference between traditional marketing and emotional marketing, we can understand the meaning and growth background of emotion in marketing. First, it is a change from passive consumers to active consumers. The digital environment has strengthened the voice of consumers. Consumers demand products according to their needs and invest in companies that match them. Second, it is a change from product to experience. At discount stores and department stores, customers often see many stories about one product. The customer now wants to buy stories that are in the product, rather than buying them, and to share their memories.

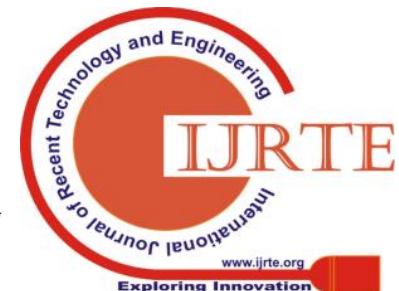


Third, it is a change from function to feeling. Quality leveling among products and intensifying competition make customers feel no difference in quality or performance anymore. Even though customers tend to pay attention to the quality of products, but they tend to be more influenced by the experience and design of the product. Fourth, communication has changed. Customers no longer want one-way messages or information, and they want to have a constant conversation to express themselves. It is evolving from one-way media to interactive media, for example, the influence of SNS is growing. Fifth, products that consumers do not want are not sold. Customer relationship management (CRM) can be developed constantly through relationship with customers, and continuous purchasing can be created. Consumers are less inclined to buy product just looking at one aspect of the product and they are demanding more. As such, it is difficult for companies to meet customer's needs with brands alone, so they need to approach customers' needs by stimulating additional customers' emotions[1].

Today, companies cannot help but find out what is an excellent means in a super-competitive situation where it is difficult to maintain customers with only goods and services. It can be the use of emotion in marketing and brand activities. This is a way of attracting consumers to the dimension of emotion and sensation, that is, the way in which the brand is born for the people and for the customers and steadily forms a more intimate and lasting relationship with them[2]. This will determine the ultimate choice of consumers and the price to pay. Emotional branding is a dynamic manifestation of imagination, sensory experience, and future-oriented approach to change. That is, emotional branding provides means and methods for connecting consumers and goods in an emotional and profound way. In other words, it focuses on the most powerful character of man who wants to experience emotional fullness beyond material satisfaction.

\section{EMOTION RELATED MARKETING CONCEPT IN MEW MARKETING ERA}

\section{A.Contents Marketing}

The growth of contents marketing is a representative phenomenon that uses emotion in new media marketing communication. Contents marketing refers to the technology that creates brand-related articles, photos, and images strategically to enable consumers to share when they need it. In other words, it can be defined as' an activity that induces consumers' interest and behavior change to a brand, product or service using various types of contents'. In contemporary society, contents are recognized as a key product that can generate profit by means of connecting social communication or by itself. Today's marketing focuses on value-oriented content that allows consumers to engage in brand activities and find value, rather than just selling products or services. Contents marketing has proven to be a key role in brand strategy as a way to attract consumers' continued interest, loyalty and engagement in their brands[3].

Contents marketing is becoming a new weapon of marketing in the age of social media. Traditionally, content marketing has been hampered by contents acceptance of consumer, talent of contents creation, and technology for distributing stories, but these obstacles have been broken down[4]. In terms of acceptance of contents, past consumers trusted only the contents of influential media, but in the age of social media, various stories are read and accepted through various media channels. Contents marketing is the process of developing and implementing valuable and relevant contents to customers in order to attract customers and generate action [5,6]. To make things easier, contents marketing is about achieving business goals by strategically creating and sharing contents [7].

Recently, major domestic and foreign companies have been paying attention to contents marketing with effective marketing techniques due to rapid change of contents consumption environment. Major companies are taking the lead in the propagation of contents marketing to achieve desired results by utilizing the influence of new media such as mobile and various platforms, away from traditional media oriented advertising methods such as TV and newspapers.

The most important advantage of content marketing is that it is interested in the content that customers are exposed to. Traditional advertising has a tendency to have rational aspect of providing information about products, but contents marketing aims to achieve desired marketing communication goals by providing emotional contents that consumers are interested in. In other words, by providing interesting or touching contents, consumers are stimulated emotionally and actively contact and spread the contents. Major domestic and overseas companies are likely to engage in contents marketing for various purposes as the role of contents grows in the context of new media marketing communication. In other words, through contents marketing, they will endeavor to maintain and build relationships with customers externally, and to contribute to enhancing corporate image and profitability internally.

\section{B. Native ads}

Native ads are kind of more active brand journalism that pays for advertising execution. Native ads are paid advertising that consumers feel that a corporate communication message is in tune with the content of the page, matches the message design well, and harmonizes with the nature of the platform. In other words, it is a corporate communication message that keeps continuity and similarity with article in three aspects of platform function, design and layout harmony, and contents characteristics[8,9]. The major characteristics of such a native ads are shown in Table 1.

Table 1 : Major Characteristics of Native Ads

\begin{tabular}{|l|l|}
\hline Characteristics & Description \\
\hline Non interruptive & $\begin{array}{l}\text { Act as part of the user } \\
\text { experience provided by the } \\
\text { media }\end{array}$ \\
\hline $\begin{array}{l}\text { In stream and } \\
\text { contextual }\end{array}$ & $\begin{array}{l}\text { Not forming a sense of } \\
\text { difference with surrounding } \\
\text { contents }\end{array}$ \\
\hline Preserves trust & $\begin{array}{l}\text { Mark explicitly that it is an } \\
\text { advertising content }\end{array}$ \\
\hline $\begin{array}{l}\text { Maintains } \\
\text { integrity }\end{array}$ & $\begin{array}{l}\text { Include content that can } \\
\text { increase corporate } \\
\text { value }\end{array}$ \\
\hline $\begin{array}{l}\text { Published By: } \\
\text { Blue Eyes Intelligence Engineering brand } \\
\text { \& Sciences Publication }\end{array}$
\end{tabular}




\begin{tabular}{|l|l|}
\hline Adds value & $\begin{array}{l}\text { Contains content that can add } \\
\text { value to the media for } \\
\text { consumers by providing } \\
\text { useful information } \\
\text { and fun }\end{array}$ \\
\hline
\end{tabular}

Internet-based new media advertising growth has resulted in diversification of commercial advertising platforms, which has diversified the forms and processes of advertising. Existing banner ads or pop-up ads are exposed in separate ad positions separated from the articles, but native ads are mixed with the articles in the form of contents similar to ordinary articles, It is the biggest feature of native ads. This allows consumers to perceive native ads as a part of their media usage that is not irresistible. Therefore, it is characteristic that native ads are optimized for the composition of a certain web site and actively acts as a part of the content that users use on the web site, unlike traditional advertising which unilaterally transmits a message[10].

Native ads are commercial message similar to the general content provided by online advertising platforms[11]. Existing online ads such as banner ads and video ads were another content designed according to the external features of the site. These special features can positively contribute to lowering the ad avoidance rate. According to the survey[12], the rate of escaping native ads compared to banner ads was $52 \%$ lower.

The concept of native ads, also called sponsored content, is media environments. The ad that appeared with increasing concern about the decrease of advertising effect by the viewer's awareness that it is watching paying contents was launched for the first time in 2012 by Facebook. Native ads has now been applied in a variety of ways through various media. Typical examples are news articles on news websites such as the New York Times and Huffington Post, and they are inserted in the form of articles and in the form of feeds and messages on various social media channels such as BuzzFeed, Gawker, Facebook, Twitter, Youtube, It is also possible to use these various channels in combination.

According to the studies related to native ads, the features of native ads are described in common as follows. First, there is an advantage that native ads can reduce the consumers' inconvenience to advertisements due to natural exposure, compared to traditional advertisements that clearly show commercial motives in advertising messages. Second, native ads shares social media platform, so it can be reproduced by many consumers, and excellent word-of-mouth effect can be expected. Third, Native ads is more popular than existing online banner ads or one - time advertisements, so it is expected strong advertising effect. Fourth, because native ads are produced and displayed using a platform specific to a specific media, it is not easy to distinguish whether it is advertisement or not[13].

Native ads are emotion based marketing communication concept in new marketing communication era. Many experts on native ads effectiveness suggest that "Native ads should provide quality content with information and fun" [14]. Native ads also argues that it is important not to convey assigned to some space on the web site, but native ads are due to the convergence of advertising concepts and social

information about goods or services but to draw emotional engagement and empathy through storytelling[15]. Specifically, research has shown that attitudes toward social media advertising are four times higher when content is emotional and entertainment than informativeness[16]. On this line, Berger \& Milkman[17] found that the spread of emotional content that stimulates emotions is much greater than neutral content in online. In sum, the effect of native ads will be highly dependent on emotional commitment and empathy. In particular, given the social media environment in which consumers are more active, emotional message element that stimulates immersion and reaction is the central determinant of native ads effectiveness.

An, Lee, \& Park[18] examined impacts of emotional appeals by social media native ads, focusing on advertorial style sponsor contents among the various types of native ads. Results showed that subjects exposed to emotional native ads revealed more positive attitudes in terms of attitudes toward the advertised products, attitudes toward brands, purchase intention toward the advertised products, purchase intention toward advertised brands, compared to those exposed to neutral native ads

\section{C.Storytelling Marketing}

Though it has become trite, it is increasingly difficult to differentiate itself from competitors in terms of the physical characteristics of products in today's marketing situations. In addition, the objective image alone is not enough to capture consumers' hearts in fierce competition. Now, companies and brands should make efforts to engrave love mark on consumer's heart. It is time to emphasize appealing to the human emotion beyond reason. In this context, storytelling marketing is a representative concept showing the importance of emotion in the new marketing communication era. Companies are using storytelling marketing to communicate effectively with consumers. They try to transmit persuasive stories by talking about facts, modifying stories or creating new stories[19]. In storytelling marketing, the type of storytelling can be divided into five types as seen in Table 2.

Table II : Types of Composition by Storytelling

\begin{tabular}{|l|l|}
\hline Types & Contents \\
\hline History storytelling & $\begin{array}{l}\text { A story in the history of a } \\
\text { company or founder }\end{array}$ \\
\hline Behind storytelling & $\begin{array}{l}\text { Hidden story about product } \\
\text { production process or service } \\
\text { process }\end{array}$ \\
\hline Experience storytelling & $\begin{array}{l}\text { A story about a product } \\
\text { experience }\end{array}$ \\
\hline Dreamketing storytelling & $\begin{array}{l}\text { Marketing to sell dreams to } \\
\text { people }\end{array}$ \\
\hline Parody storytelling & $\begin{array}{l}\text { Transmitting messages by } \\
\text { following the } \\
\text { works of famous writers }\end{array}$ \\
\hline
\end{tabular}

Recently, the importance of storytelling marketing is getting more and more important as consumers' purchasing factors move from product center to center of emotion.

Published By:

Blue Eyes Intelligence Engineering 
Storytelling marketing is a marketing method that actively informs consumers about the story of a product. It tells stories that are hidden in the product that the public does not know about rather than informing the product itself, thereby making the memory of the brand clearer. It refers to the emotional marketing activities that induce the sympathy of the brand. In other words, storytelling marketing is subjective and emotional communication that brings about immersion and fun by presenting the meaning and personal story contained in the product, not introducing the product itself. By introducing stories into marketing activities, it is not merely buying things, but is emotion-oriented marketing activities that let people enjoy the stories contained in them.

Storytelling is widely used as a technique to transmit messages by utilizing the power of narrative structure. The storytelling method, which is mainly applied in the field of cultural contents, is being actively applied in various fields in recent years. Recently, storytelling has been used as a marketing tool in various fields such as advertising, game, local marketing, and tourism product development. Storytelling has been recognized as being far from the management and marketing in the past because it has an emotional and fanciful character. However, as the importance of emotion is recognized recently, it is being used for persuasion of customers. It is also used as a communication device to share value.

As the power of various online media has increased, storytelling marketing has widened its scope. In particular, interactive media, such as the Internet, have had a huge impact on expanding the storytelling marketing[20]., and storytelling marketing is widely used as a technique to transmit messages by utilizing the power of narrative structure. The storytelling method, which is mainly applied in the field of cultural contents, is being actively applied in various fields in recent years. Recently, storytelling has been used as a marketing tool in various fields such as advertising, game, local marketing, and tourism product development. Storytelling has been recognized as being far from the management and marketing in the past because it has an emotional and fanciful character. However, as the importance of emotion is recognized recently, it is being used for persuasion of customers. It is also used as a communication device to share value.

\section{APPLICATION DIRECTION OF EMOTION TO MARKETING COMMUNICATION IN THE FUTURE}

In new marketing communication era, the application of emotion to marketing communication will increase. What is important is the direction of application of emotion to marketing communication. In this chapter important directions of application will be discussed. First direction is collaboration. For effective application of emotion to marketing communication, the collaboration with other field is necessary. As typical emotion based marketing communication concept are contents marketing, native ads, and storytelling marketing, collaboration with culture, art, sports, etc. is very important for the success of effective application of emotion to marketing communication. In recent years, collaboration with new areas such as fashion, film and

science has been increasing in the production of commercial contents. In the course of such an integrated collaboration, for creating successful commercial content, it is recommended for marketers and advertising representatives to present only a rough concept and direction, and ensure that creative freedom is provided for partners to demonstrate their creativity. Therefore, in order to increase the effectiveness of commercial contents in the advertising and public relations industry, it is necessary to cooperate with experts in various fields in a longer-term perspective.

Second direction for effective application of emotion to marketing communication is creativity. Like advertising, the creativity is important in the use of emotion in marketing communication. Lately, media creative is standing out in new marketing communication environment. In other words, using new method and new media in emotion based marketing communication is important for the success of emotion based marketing communication. It requires drastic challenges to change, and it needs to openly accept creative work beyond the existing framework. It is necessary to boldly break away from the past way of allocating the budget and distributing the contents. Also, if the direction is right, ensuring maximum autonomy for the collaboration partner will be an effective approach. It is important to differentiate the way to deliver emotional contents to consumers. It has become important to deliver creative emotional contents that can satisfy an individual's emotional desires beyond the consumer's cognitive desires. It can be seen that consumers' responses to emotional contents vary depending on the way of delivering emotional contents of a similar theme.

The third application direction of emotion to marketing communication is long term perspective. The goal of emotional marketing or emotional communication is not short term sales increase. They should be viewed as a variety of efforts to engage with consumers rather than immediate results or effects. This implies that much time and effort must be invested. Emotional marketing and emotional communication are not just one-off sales, but ultimately they should maintain long-term relationships with individual customers. In other words, management recognizes that it is a process of understanding and gaining a customer, not a one-time event, and management should be willing to invest a long term in loyalty. It should be helpful to mutual benefit, and reliability must be based on to maintain a lasting relationship. Also, relationships based on trust will contribute to the development of long-term relationships. The relationship between a company and a customer should be a continuous partnership as a customer relationship management that transcends the relationship between production and consumption.

The forth application direction of emotion to marketing communication is relevance with brand. Relevance with brand is very important factor for the success of new marketing communication media including CSR, ICT-based advertising beside emotional marketing or emotional communication. 
Even though emotional marketing or emotional communication is fun, touching, and creative, if it has no relation with brand, desired goal cannot be accomplished. In the floods of many brands, brands are born for customers. It is the emotional sharing of the brand that continues to maintain intimacy with consumers. Emotional sharing is a futuristic approach to consumers imagination, sensory experience and change, and is a means of attracting consumers. That is, the starting point of all emotional contents is the brand. Even now, many practitioners simply create new contents that are not suited to solving their problems by following the fashion without a clear understanding of the situation of their brand. It is important to recognize that there are no effective emotional contents without clear definition of a brand and marketing problem. Emotional contents must be clear in purpose and information expertise is required according to purpose. Differentiation of emotional contents for competitiveness is obviously important, but it is also important to design the contents within an appropriate range that is relevant to the brand. Companies should plan contents with clear purpose after considering various aspects such as the field of the brand, the value to be aimed at. Application direction of emotion to marketing communication in the future can be summarized as seen in Table 3 .

Table III : Application Direction of Emotion to Marketing Communication in the Future

\begin{tabular}{|c|c|}
\hline Direction & Description \\
\hline Collaboration & $\begin{array}{l}\text { For effective application of emotion to } \\
\text { marketing communication, the } \\
\text { collaboration with other field is necessary }\end{array}$ \\
\hline Creativity & $\begin{array}{l}\text { Like advertising, the creativity is } \\
\text { important in the application of emotion to } \\
\text { marketing communication }\end{array}$ \\
\hline $\begin{array}{l}\text { Long term } \\
\text { perspective }\end{array}$ & $\begin{array}{l}\text { Application of emotion in marketing } \\
\text { communication should be viewed as a } \\
\text { variety of efforts to engage with } \\
\text { consumers in long term }\end{array}$ \\
\hline $\begin{array}{l}\text { Relevance with } \\
\text { brand }\end{array}$ & $\begin{array}{l}\text { Even though emotional marketing or } \\
\text { emotional communication is fun, } \\
\text { touching, and creative, if it has no relation } \\
\text { with brand, desired goal cannot be } \\
\text { accomplished }\end{array}$ \\
\hline
\end{tabular}

\section{RESUltS}

This study examined the use of emotion in the recent new marketing communication era. This study first examined the concept of emotion, and the meaning of emotion in marketing and brand.

\section{CONCLUSION}

This study examined the use of emotion in the recent new marketing communication era. This study first examined the concept of emotion, and the meaning of emotion in marketing and brand. Emotion is a personal and subjective feeling that is instantly and automatically experienced when perceiving an object, or when in a particular environment. Emotion is ambiguous feeling which is inherently complex and comprehensive, and has personal and dynamic characteristics.

Today, companies cannot help but find out what is an excellent means in a super-competitive situation where it is difficult to maintain customers with only goods and services. It can be the use of emotion in marketing and brand activities. This is a way of attracting consumers to the dimension of emotion and sensation, that is, the way in which the brand is born for the people and for the customers and steadily forms a more intimate and lasting relationship with them.

Emotion based marketing communication concepts in new marketing communication era are scrutinized. The growth of contents marketing is a representative phenomenon that uses emotion in new media marketing communication. Contents marketing refers to the technology that creates brand-related articles, photos, and images strategically to enable consumers to share when they need it. Native ads are emotion based marketing communication concept in new marketing communication era. Native ads are paid advertising that consumers feel that a corporate communication message is in tune with the content of the page, matches the message design well, and harmonizes with the nature of the platform. After the information age, it is the opinion that providing dreams and emotions to consumers will be the core of brand and company differentiation. So storytelling marketing is typical emotion based marketing communication concept. Storytelling marketing is a marketing method that actively informs consumers about the story of a product. It tells stories that are hidden in the product that the public does not know about rather than informing the product itself, thereby making the memory of the brand clearer.

This study proposed the application direction of emotion to marketing communication in the future. First, for effective application of emotion to marketing communication, the collaboration with other field including culture, art, and sports, etc. is necessary. Second, like advertising, the creativity is important in the application of emotion to marketing communication. In other words, using new method and new media in emotion based marketing communication is important for the success of emotion based marketing communication. Third, application of emotion in marketing communication should be viewed as a variety of efforts to engage with consumers in long term. The forth application direction of emotion to marketing communication is relevance with brand. Even though emotional marketing or emotional communication is fun, touching, and creative, if it has no relation with brand, desired goal cannot be accomplished.

In marketing communication, the use of emotion is meaningful in creating good feelings, leading consumers to unconscious responses, and linking them to sales growth by embodying stimulation which match with consumer's emotion in the form of a five senses. The application of emotion in marketing communication can increase the appeal of the message by naturally bringing spontaneous emotional response of the customer, and it will be used actively for the future because it has the advantage of long lasting effect, 
and it is likely to become a key dimension of competitive advantage. In the situation where it is difficult to differentiate brand from others by quality of products, and where the effect of traditional marketing communication is not same as before, marketing communication using emotion will become a major means of brand differentiation, and it will become more important in marketing and corporate communication.

\section{ACKNOWLEDGMENT}

Funding for this paper was provided by Namseoul University.

\section{REFERENCES}

1. Y. H. Bae, "The case study on the emotional marketing of enterprise : Focused on broadcasting advertising," Korean Review of Corporation Management, vol. 3, no. 1, 2013, pp. 25-41.

2. S. U. Nam and B. R. Park, "A study on the strategy of content marketing using YouTube," Design Convergence Study, vol. 16, no. 2, 2017, pp. 63-81.

3. S. G. Moon, "A study on the emotional approach as brand communication," Journal of Korea Design Forum, vol. 23, 2009, pp. 57-66.

4. J. Pulizzi, "The rise of storytelling as the new marketing" Publishing Research Quarterly, vol. 28, no. 2. 2012, pp. 116-123.

5. Curata, 2014 Content marketing tactics planner: Creation, curation \& syndication, 2014.

6. IAB, Content marketing primer, 2013a.

7. B. Clay, M. "Newlands, Content marketing strategies for professionals: How to use content marketing, communicate with impact, generate sales, and get found by search engines.," North Charleston, CreateSpace Independent Publishing Platform, 2014.

8. B. W. Wojdynski and N. J. Evans, "Going native: Effects of disclosure position and language on the recognition and evaluation of online native advertising," Journal of Advertising, vol. 45, no. 2, 2016, pp157-168. http://dx.doi.org/10.1080/00913367.2015.1115380

9. G. Y. Lee and J. H. Jung, "A study on the types of communication design in digital native advertising," Journal of Brand Design Association of Korea, vol. 15, no. 2, 2017, pp31-42. http://doi.org/10.18852/bdak.2017.15.2.31

10. J. Son and I. Kang, "The Effect of Native Advertising Credibility on Social Media Advertising Effectiveness," The e-Business Studies, vol. 18, no. 3, 2017, pp21-37. http://doi.org/10.20462/TeBS.2017.06.18.3.21

11. IAB, The native advertising playbook, $2013 \mathrm{~b}$.

12. IPG Media Lab \& Sharethrough, Exploring the Effectiveness of Native Ads. http://www.iab.net/media/file/Sharethrough-IPG-Infograpic-11x17-CM YK_nobleeds.pdf

13. Y. S. Kim and H. M. Choi, "Consumer-brand relationship quality formation of potential consumers for an automotive brand: Effectiveness of native advertising," Journal of the Korea Contents Association, vol. 17, no. 2, 2017, pp656-677. http://doi.org/10.5392/JKCA.2017.17.02.656

14. IPG Media Lab, Exploring the Effectiveness of Branded Content, 2013. https://www.ipglab.com/wp-content/uploads/2013/10/Effectiveness-ofBra

15. R, Lieb, J. Szymanski, and S. Etlinger, Defining and mapping the native advertising landscape, 2013. https://www.americanpressinstitute.org/wp-content/uploads/2013/10/re port-defining-mapping-native-advertising-landscape-rebecca-lieb.pdf.

16. D. G. Taylor, J. E. Levin, and D, Strutton "Friends, fans, and followers: Do ads work on social networks? How gender and age shape receptivity," Journal of Advertising Research, vol. 51, no. 1, 2011, pp258-275. http://dx.doi.org/10.2501/JAR-51-1-258-275

17. J. Berger and K. L. Milkman, "What makes online content viral?," Journal of Marketing Research, vol. 49, no. 2, 2012, pp192-205. http://dx.doi.org/10.1509/jmr.10.0353

18. S. An, H. Lee, and H, Park, "Impacts of Emotional Appeals by Social Media Native Ads: Psychological Arousal and Advertising Effects," Journal of Broadcasting and Telecommunications Research, vol. 95, 2011, pp112-145.

19. S. Kim, "A Study on the usefulness of storytelling marketing in brand space" Journal of Korea Design Forum, vol. 23, 57-66, 2009.
20. M. H. Lee and J. M. Lee, "Online Storytelling Marketing" Business Management Research, vol. 4, no. 2, 77-103, 2011.

\section{AUTHORS PROFILE}

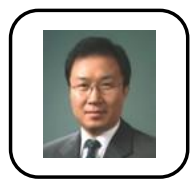

Min-Wook Choi is currently working as Associate Professor with Namseoul University, Cheonan, South Korea. He has completed Ph.D from Hanyang University, Seoul, South Korea. He has received 2018 Albert Nelson Marquis Lifetime Achievement Award. He had worked as $(1989-2002)$. an Account Manager in companies including Oricom 